\title{
Cortical thickness of the tibial diaphysis reveals age- and sex-related characteristics between non-obese healthy young and elderly subjects depending on the tibial regions
}

Keisuke Maeda', Tomoharu Mochizuki ${ }^{1 *}$ (D), Koichi Kobayashi², Osamu Tanifuji', Keiichiro Someya ${ }^{1}$, Sho Hokari ${ }^{1}$, Ryota Katsumi ${ }^{1}$, Yusuke Morise ${ }^{3}$, Hiroshi Koga ${ }^{1}$, Makoto Sakamoto², Yoshio Koga ${ }^{4}$ and Hiroyuki Kawashima ${ }^{1}$

\begin{abstract}
Purpose: This study aimed to evaluate the age- and sex-related characteristics in cortical thickness of the tibial diaphysis between non-obese healthy young and elderly subjects as reference data.

Methods: The study investigated 31 young subjects (12 men and 19 women; mean age, $25 \pm 8$ years) and 54 elderly subjects ( 29 men and 25 women; mean age, $70 \pm 6$ years). Three-dimensional estimated cortical thickness of the tibial diaphysis was automatically calculated for 5000-9000 measurement points using the high-resolution cortical thickness measurement from clinical computed tomography data. In 12 assessment regions created by combining three heights (proximal, central, and distal diaphysis) and four areas of the axial plane at $90^{\circ}$ (medial, anterior, lateral, and posterior areas) in the tibial coordinate system, the standardized thickness was assessed using the tibial length.
\end{abstract}

Results: As structural characteristics, there were no differences in the medial and lateral thicknesses, while the anterior thickness was greater than the posterior thickness in all groups. The sex-related difference was not shown. As an age-related difference, elderly subjects showed greater or lesser cortical thickness than the young subjects, depending on the regions of the tibia.

Conclusions: Cortical thickness was different depending on sex, age, and regions in the tibia. The results of this study are of clinical relevance as reference points to clarify the causes of various pathological conditions for diseases.

Level of evidence: Level 3.

Keywords: Age, Sex, Cortical bone, Tibia

* Correspondence: tommochi121710@gmail.com

${ }^{1}$ Division of Orthopedic Surgery, Department of Regenerative and Transplant Medicine, Niigata University Graduate School of Medical and Dental Science,

1-757 Asahimachi-dori Chuo-ku, Niigata City, Niigata 951-8510, Japan

Full list of author information is available at the end of the article

(c) The Author(s). 2020 Open Access This article is licensed under a Creative Commons Attribution 4.0 International License, which permits use, sharing, adaptation, distribution and reproduction in any medium or format, as long as you give appropriate credit to the original author(s) and the source, provide a link to the Creative Commons licence, and indicate if changes were made. The images or other third party material in this article are included in the article's Creative Commons licence, unless indicated otherwise in a credit line to the material. If material is not included in the article's Creative Commons licence and your intended use is not permitted by statutory regulation or exceeds the permitted use, you will need to obtain permission directly from the copyright holder. To view a copy of this licence, visit http://creativecommons.org/licenses/by/4.0/. 


\section{Introduction}

Three-dimensional cortical bone thickness varies depending on the regions of the bone [1] and is the optimal parameter to evaluate structural adaptation by biological factors and mechanical use [2]. A bone's resistance is dependent on the sex- and age-related characteristics of cortical thickness [3, 4], which is useful in determining the causes of various pathological conditions, such as knee osteoarthritis (OA) [5-11].

Our group has been conducting an epidemiological study with regard to knee OA in Matsudai district of Tokamachi City in Niigata Prefecture in seven-year intervals since 1979 (Matsudai Knee Osteoarthritis Survey) [12-18]. The epidemiological study has the advantage of clarifying the sequence of changes and causes of initiation and progression. This cohort demonstrated that tibial cortical thickness is one of the key factors in clarifying the etiology of knee OA [5].

Measuring cortical thickness and volumetric density is challenging by clinical low-resolution computed tomography $(\mathrm{CT})$. Simple thickness estimates based on several measures [19-22] have not provided optimal measurements. To date, Treece et al. [23, 24] reported highly accurate measurements by which cortical thickness can be accurately estimated from the clinical low-resolution CT data, using the mathematical model of the anatomy and imaging system (Figs. 1 and 2) [23, 24].
Data regarding cortical thickness to evaluate bony deformity and to elucidate the etiology of pathological conditions in the lower extremity, such as knee OA, is important. A previous study reported the age- and sexrelated characteristics of cortical thickness in the femoral diaphysis for healthy subjects as reference data [1]; however, control data of the tibial diaphysis remains unknown.

This study aimed to identify the age- and sex-related characteristics of three-dimensional cortical thickness of the tibial diaphysis in healthy non-obese young and elderly individuals, using high-resolution cortical thickness measurement from clinical CT data. The hypothesis was that the cortical thickness of the tibial diaphysis would show age- and sex-related characteristics depending on the tibial regions.

\section{Materials and methods Subjects}

The inclusion criteria were healthy elderly (age $>50$ years) and healthy young (age $<50$ years) subjects who were not obese [body mass index (BMI) <30]. The exclusion criteria were not subjects with obesity (BMI > 30), history of trauma, knee OA, or other diseases that influence cortical thickness, such as osteometabolic diseases, except for primary osteoporosis.

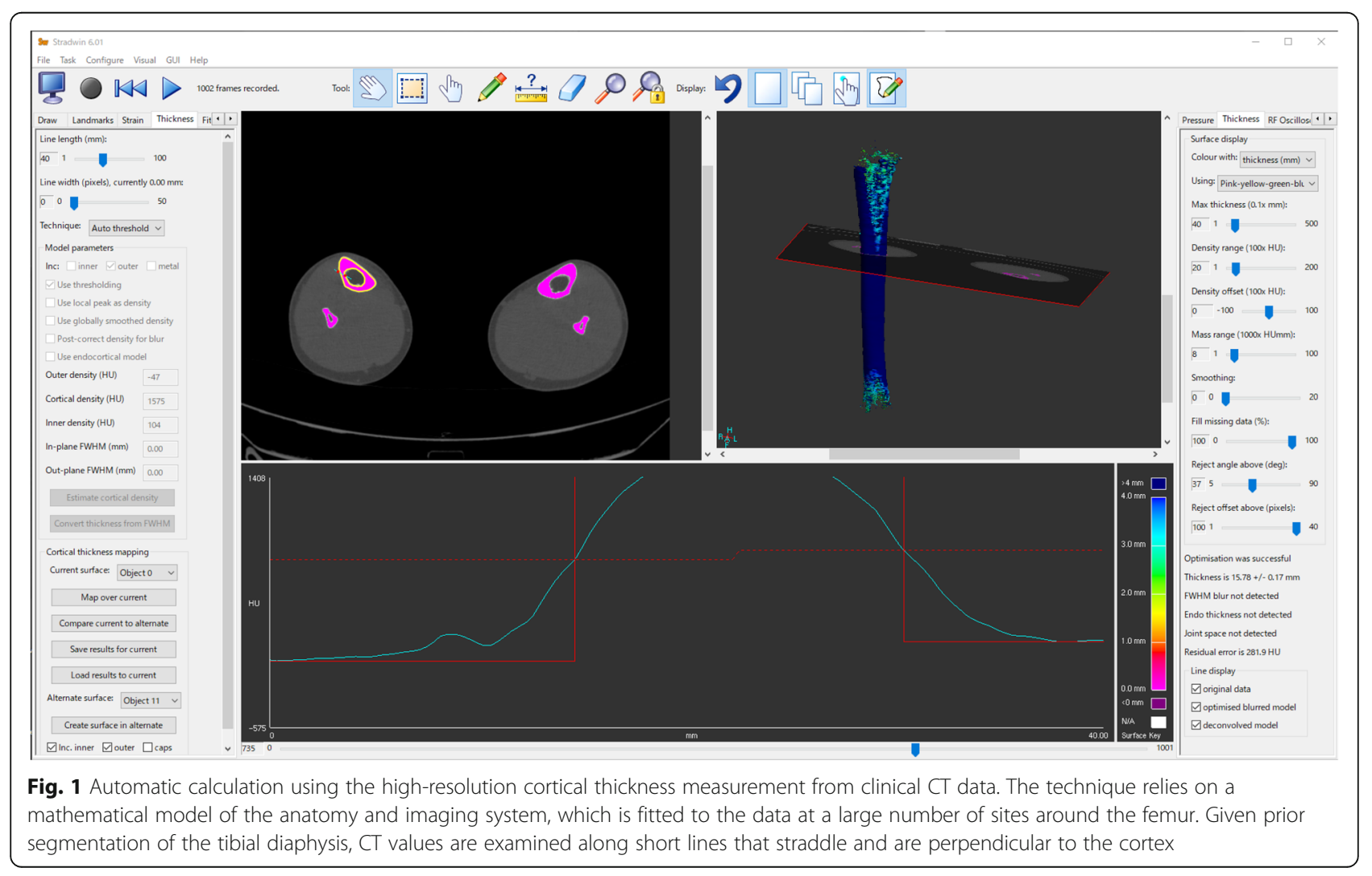




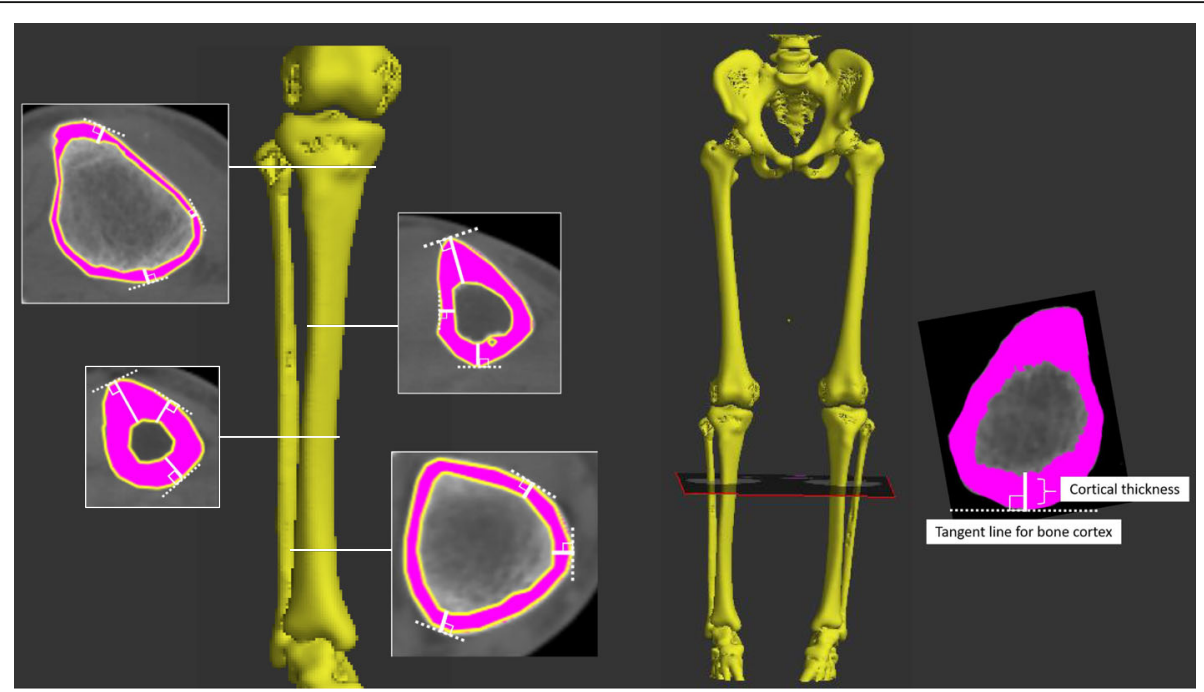

Fig. 2 Schematic illustration of the three-dimensional bone models and tibial cortical thickness mapped back onto the surface as a color. Cortical thickness of the tibia can be mapped across the entire surface of the tibia using a cortical mapping technique

First, a total of 107 elderly Japanese volunteers who had no knee complaints or histories of joint disease or major injury in the lower extremity were publicly recruited. The volunteers did not have any competing interests and were not paid fees. Physicians assessed their general and lower extremity conditions using physical tests and radiographs and excluded seven subjects with radiographic evidence of knee OA. Out of 100 healthy elderly patients (50 men and 50 women) with grades $0-1$ on the Kellgren-Lawrence
$(\mathrm{K}-\mathrm{L})$ classification and absence of radiographic knee OA, 54 elderly (aged $>50$ years) Japanese volunteers $(29$ men and 25 women) were randomly selected in this study (Fig. 3). Two orthopedic surgeons (graders) who were not provided with any clinical information of the patients performed the $\mathrm{K}-\mathrm{L}$ classification. When the same subject was assigned different grades, the graders discussed and determined a common $\mathrm{K}-\mathrm{L}$ grade. The average age \pm standard deviation (SD) (range) of the elderly men and women was
Elderly subjects

107 elderly volunteers $>50$ years old

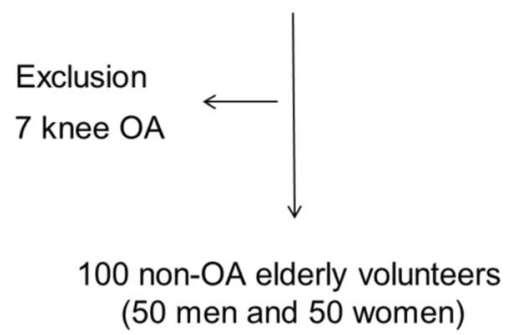
54 non-OA elderly volunteers ( 29 men and 25 women)

Exclusion

1. Obese $>30$ of BMI

2. Skeletal dysplasia

3. No CT data

\section{Young subjects}

2009-2019 operating records 1120 patients (515 men and 605 women)

Exclusion $\longleftarrow 25$ patients $>50$ years old $\longleftarrow$

$17-49$ years old: 395 patients (232 men and 163 women)

\section{Random selection}

31 patients(12 men and 19 women) of

$28 \mathrm{ACL}, 2$ patellar instability, and 1 bone fracture

Fig. 3 Inclusion and exclusion criteria of the subjects. OA: osteoarthritis, BMl: body mass index, ACL: anterior cruciate ligament 
$71 \pm 6$ years (61 to 83 years) and $68 \pm 5$ years (60 to 83 years), respectively. The average $\mathrm{BMI} \pm \mathrm{SD}$ (range) of the elderly men and women was $23.0 \pm 2.0 \mathrm{~kg} / \mathrm{m}^{2}$ (17.6 to $\left.27.0 \mathrm{~kg} / \mathrm{m}^{2}\right)$ and $20.0 \pm 1.6 \mathrm{~kg} / \mathrm{m}^{2}\left(17.1\right.$ to $\left.23.0 \mathrm{~kg} / \mathrm{m}^{2}\right)$, respectively.

In young participants (age $<50$ years), 395 out of 1120 patients were initially selected from the medical operating records of 2009-2019. Obese participants (BMI > 30 ), those with diseases that influence cortical thickness, such as skeletal dysplasia, infection, and osteometabolic disease, and those with no CT or BMI data were excluded. Finally, the lower extremities of 31 healthy young Japanese participants (12 men and 19 women) were randomly selected from 395 patients aged $<50$ years using the abovementioned exclusion criteria. Data from the contralateral side of the patients with 28 anterior cruciate ligament injuries, two patellar instabilities, and one traumatic bone fracture are included in Fig. 3. The average age \pm SD (range) was $26 \pm 6$ years (20 to 39 years) and $25 \pm 9$ years (17 to 41 years) in the young men and women, respectively. The average $\mathrm{BMI} \pm \mathrm{SD}$ (range) was $22.1 \pm 1.4 \mathrm{~kg} / \mathrm{m}^{2}\left(20.0-24.1 \mathrm{~kg} / \mathrm{m}^{2}\right)$ and $22.2 \pm 2.6$ $\mathrm{kg} / \mathrm{m}^{2}\left(17.7-27.7 \mathrm{~kg} / \mathrm{m}^{2}\right)$ in young men and women, respectively.

\section{CT scanning condition}

CT scans with a 1-mm interval in the lower extremities from the femoral head to the ankle joint were performed in two institutions, for the young subjects using Somatom Sensation 16 (Siemens Inc., Munich, Germany) in our university and for the elderly subjects using Canon Aquilion 64 CT scanner (Canon Medical Systems, Tochigi, Japan) in the other institution. The scans were obtained at a tube voltage of $120 \mathrm{kVp}$ and current of $50-400 \mathrm{~mA}$. The field of view, matrix, and pixel parameters were $350-400 \mathrm{~mm}, 512 \times 512$, and $0.68-0.78 \mathrm{~mm} /$ pixel, respectively. The voxel size was $0.68 \times 0.68 \times 1.00 \mathrm{~mm}$ to $0.78 \times 0.78 \times 1.00 \mathrm{~mm}$. For CT radiation, the mean dose length product was $896.7 \pm$ $129.9 \mathrm{mGy} \times \mathrm{cm}$.

\section{Calculation of cortical thickness $[23,24]$}

Cortical thickness of the tibial diaphysis was automatically calculated in a three-dimensional space using highresolution measurement reported by Treece et al. [23, 24] (Figs. 1 and 2), which allows for accurate estimates of cortical thickness based on an estimate of cortical density. This software has been primarily used to analyze the cortical thickness of the femoral neck because the hip fracture has consisted in problems in clinical practice [3, 23]. The technique was implemented using Stradwin software (version 5.3; Medical Imaging Group, Machine Intelligence Laboratory, Cambridge Engineering Department, Cambridge, UK), which is available for free download and is a new tool with a demonstrated subvoxel accuracy in assessing cortical bone properties using routine low-resolution $\mathrm{CT}$. The method uses a complex model-based fit approach using the mathematical model of the anatomy and imaging system, calculates from thousands of data points across the bone surface, and assesses using semi-automatic segmentation [23]. The creation of the surface and use of surface normals to guide thickness estimation were performed as follows (Figs. 1 and 2): a surface was generated by thresholding the entire dataset and extracting the contours in each plane to subpixel resolution. Then, contours were edited locally to correct erroneously excluded regions and remove adjoining structures. A surface was interpolated through these contours, and surface vertices and normals were used to guide in-plane thickness estimates by a mathematical equation. The number of measurement points per subject was 50009000, depending on the tibial length. Cortical thickness was calculated for each point. Given prior segmentation of the tibia, CT values (Hounsfield units) were examined along the short lines that straddle and are perpendicular to the cortex. Once cortical thickness was estimated at each vertex, this was mapped back onto the surface as a color using a cortical bone mapping technique (Fig. 2). A high-resolution thickness map was filtered over the surface.

Regarding accuracy, Treece et al. [23] tested the validity of the constant-density assumption by measuring the true density of cadaveric femurs in high-resolution $\mathrm{CT}$, which is approximately seven times the resolution of low-resolution scans. They reported that cortical bone thickness estimates were accurate up to $0.3 \mathrm{~mm}$. The technique was also validated in vivo in the context of osteoporosis and hip fractures within laminar structures $[3,23]$.

\section{Anatomical tibial coordinate system}

An anatomical coordinate system for the tibia was constructed using our original software (Fig. 4). First, the three-dimensional CT tibial model was downloaded, and the temporal $z$-axis was defined as the axis connecting two centers of the approximated circles in the tibial diaphysis at two transverse planes. Second, the line connecting the attachment of the posterior cruciate ligament with the medial edge of the tibial tuberosity was defined as the $y$-axis (positive anteriorly). The crossproduct of the temporal $z$-axis and $y$-axis was defined as the tibial $x$-axis (positive right). Finally, the crossproduct of the $y$-axis and $x$-axis was the true tibial $z$-axis (positive superiorly). The origin point of the tibial coordinate system was defined as the cross-point between the distal tibial articular surface and the true $z$-axis. 


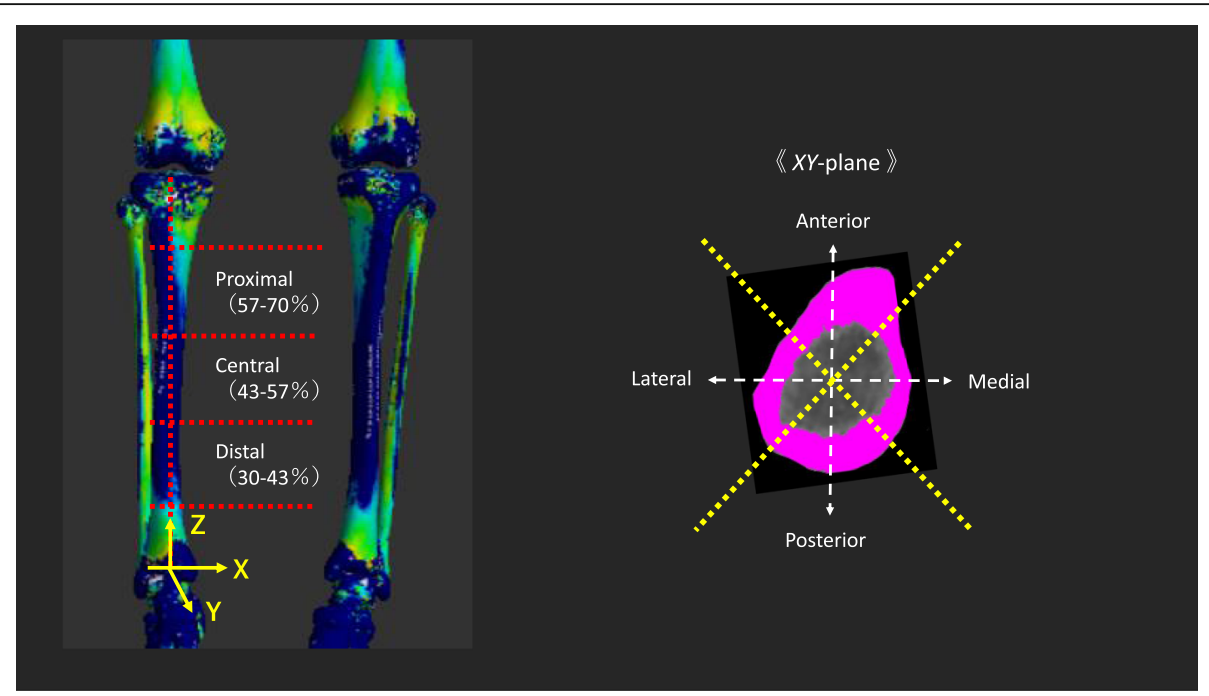

Fig. 4 Schematic illustration of the tibial coordinate system and 12 regions divided by each of the three heights (proximal, central, and distal) and four areas (medial, anterior, lateral, and posterior). An anatomical coordinate system of the tibia was constructed. Twelve regions were created by combining three heights (proximal, 57\%-70\%; central, 43\%-57\%; distal, 30\%-43\%) and four areas of the axial plane (xy-plane) at 90 (medial, anterior, lateral, and posterior), comprising cortical thickness data from 200 to 1000 points in each region

\section{Evaluation parameters}

Twelve regions were created by combining three heights (proximal, 57\%-70\%; central, 43\%-57\%; distal, 30\%$43 \%)$ and four areas of the axial plane ( $x y$-plane) at $90^{\circ}$ (medial, anterior, lateral, and posterior) (Fig. 4). Height was defined as follows: the tibial length was defined from the midpoint of the tibial eminences to the midpoint of the medial and lateral points on top of the talar dome, presenting $100 \%$ of the tibial length. The tibial diaphysis was defined as $30 \%-70 \%$, divided into three heights, and categorized by $17 \%$ (proximal, $57 \%-70 \%$; central, $43 \%-$ $57 \%$; distal, 30\%-43\%). Each of the 12 regions (three heights $\times$ four areas in the $x y$-plane) comprised cortical thickness data from 200 to 1000 points. The assessment parameter was the average of the cortical thickness data from 200 to 1000 points in each region in the tibial diaphysis, divided by each height and area. The cortical thickness in each of the 12 regions was compared among the four groups categorized by sex and age (young men, young women, elderly men, and elderly women). When data were compared, standardized values, not actual values, were applied. The standardized values divided by the tibial length (cortical thickness/tibial length) were applied because cortical thickness is influenced by body constitution (body weight and height). To standardize the values, as the unit of the values must be identical, the tibial length proportional to the body height, not body weight, was selected.

\section{Precision and reproducibility through all processes}

To ensure precision and test-retest reliability of the measurement of cortical thickness in a three-dimensional space through all processes, two researchers performed two measurements as one set in 10 subjects randomly selected from each group. CT was performed once in each subject so that the precision in this study excluded CT scanning conditions. The precision for cortical thickness of the total diaphysis was calculated as follows:

$\frac{(\mid 1 \text { st }-2 \text { nd } \mid) \operatorname{case} 1+() \operatorname{case} 2+() \text { case3 }+() \text { case4 }+() \text { case } 5 \cdots \cdot() \text { case10 }}{10}$

Mean differences and 95\% confidence intervals (CIs) of the differences in the standardized cortical thickness of the total diaphysis were calculated. The mean and maximum differences were $0.1 \times 10^{-3}$ and $0.3 \times 10^{-3}$ for researcher $\# 1$ and $0.01 \times 10^{-3}$ and $0.03 \times 10^{-3}$ for researcher \#2, respectively. The $95 \% \mathrm{CI}$ of the differences was $0.0 \times 10^{-3}-0.1 \times 10^{-3}$ for researcher $\# 1$ and 0.0 $0.02 \times 10^{-3}$ for researcher $\# 2$, respectively. In the testretest reliability (SPSS version 21, SPSS Inc., Chicago, IL, USA), intraobserver reproducibility via the intraclass correlation coefficient of the two measurements was $0.925(p<0.001)$ for researcher \#1 and $0.998(p<0.001)$ for researcher $\# 2$. Interobserver reproducibility via the interclass correlation coefficient was $0.989(p=0.001)$.

This study was performed based on a protocol approved by the institutional review board of Niigata University. The IRB number was 2015-2351. All subjects provided written or verbal informed consent for study participation and use of their data.

\section{Statistical analyses}

Actual and standardized values are shown in Tables 1 and 2. Comparing the standardized values, one-way 
Table 1 Cortical thickness in the tibial diaphysis (actual values)

\begin{tabular}{|c|c|c|c|c|c|c|c|c|}
\hline \multirow{3}{*}{$\begin{array}{l}\text { Actual } \\
\text { values } \\
(\mathrm{mm})\end{array}$} & \multicolumn{4}{|c|}{ Young group $(n=31)$} & \multicolumn{4}{|c|}{ Elderly group $(n=54)$} \\
\hline & \multicolumn{2}{|c|}{ Men $(n=12)$} & \multicolumn{2}{|c|}{ Women $(n=19)$} & \multicolumn{2}{|c|}{ Men $(n=29)$} & \multicolumn{2}{|c|}{ Women $(n=25)$} \\
\hline & mean & $95 \% \mathrm{Cl}$ & mean & $95 \% \mathrm{Cl}$ & mean & $95 \% \mathrm{Cl}$ & mean & $95 \% \mathrm{Cl}$ \\
\hline \multicolumn{9}{|c|}{ Total diaphysis } \\
\hline Medial & 5.7 & $5.4-6.0$ & 5.1 & $4.7-5.5$ & 5.7 & $5.5-5.9$ & 5.6 & $5.5-5.8$ \\
\hline Lateral & 6.2 & $5.5-6.8$ & 4.7 & $4.5-5.0$ & 5.6 & $5.4-5.8$ & 5.4 & $5.2-5.6$ \\
\hline Anterior & 10.2 & $8.9-11.5$ & 8.2 & $7.7-8.8$ & 7.9 & $7.5-8.2$ & 7.3 & $7.0-7.6$ \\
\hline Posterior & 6.4 & $5.9-6.8$ & 5.8 & $5.3-6.3$ & 5.3 & $5.2-5.5$ & 5.0 & $4.8-5.1$ \\
\hline \multicolumn{9}{|c|}{ Proximal diaphysis } \\
\hline Medial & 5.1 & $4.8-5.3$ & 4.6 & $4.3-4.9$ & 5.6 & $5.4-5.8$ & 5.5 & $5.3-5.7$ \\
\hline Lateral & 5.5 & $4.9-6.1$ & 4.2 & $4.0-4.4$ & 5.5 & $5.3-5.7$ & 5.3 & $5.0-5.6$ \\
\hline Anterior & 8.9 & $7.4-10.3$ & 7.3 & $6.7-8.0$ & 7.3 & $7.0-7.7$ & 7.1 & $6.8-7.4$ \\
\hline Posterior & 6.2 & $5.7-6.7$ & 5.4 & $4.9-5.8$ & 5.3 & $5.1-5.4$ & 5.1 & $4.9-5.3$ \\
\hline \multicolumn{9}{|c|}{ Central diaphysis } \\
\hline Medial & 5.9 & $5.4-6.4$ & 5.3 & $4.8-5.8$ & 5.7 & $5.4-6.0$ & 5.7 & $5.4-5.9$ \\
\hline Lateral & 6.6 & $5.7-7.5$ & 5.1 & $4.6-5.5$ & 5.4 & $4.9-5.8$ & 5.4 & $5.1-5.7$ \\
\hline Anterior & 11.3 & $10.0-12.6$ & 9.3 & $8.6-10.0$ & 8.3 & $7.8-8.8$ & 7.2 & $6.5-7.9$ \\
\hline Posterior & 6.7 & $6.2-7.2$ & 6.2 & $5.6-6.7$ & 5.3 & $5.1-5.5$ & 4.8 & $4.7-4.9$ \\
\hline \multicolumn{9}{|c|}{ Distal diaphysis } \\
\hline Medial & 6.3 & $5.9-6.8$ & 5.9 & $5.3-6.5$ & 6.1 & $5.8-6.4$ & 5.9 & $5.7-6.1$ \\
\hline Lateral & 6.7 & $5.9-7.5$ & 5.2 & $4.8-5.6$ & 5.9 & $5.5-6.3$ & 5.6 & $5.3-6.0$ \\
\hline Anterior & 11.0 & $9.6-12.3$ & 8.4 & $7.8-9.0$ & 8.9 & $8.3-9.5$ & 7.6 & $7.2-8.1$ \\
\hline Posterior & 6.2 & $5.7-6.7$ & 6.0 & $5.5-6.6$ & 5.6 & $5.3-5.8$ & 4.8 & $4.7-4.9$ \\
\hline
\end{tabular}

95\%Cl 95\% Confidence interval

analysis of variance (ANOVA) with post hoc test (Tukey) was applied (Tables 3 and 4). In Table 3, the standardized cortical thickness in each height (proximal, central, and distal diaphysis) of the four groups (young men, young women, elderly men, and elderly women) was compared among the four areas of the transverse plane (medial, anterior, lateral, and posterior areas), using one-way ANOVA with Tukey test. In Table 4, the standardized cortical thickness in each of the 12 regions was compared among the four groups categorized by sex and age (young men, young women, elderly men, and elderly women) using one-way ANOVA with Tukey test. Statistical significance was set at a $p$-value $<0.01$ (SPSS version 21, SPSS Inc., Chicago, IL, USA). The results of a power analysis for one-way ANOVA among the four groups (young men, young women, elderly men, and elderly women) were as follows: proximal-medial area, power $=1.000, \quad p<0.001$; $\quad$ proximal-anterior area, power $=0.266, p=0.392$; proximal-lateral area, power $=$ 1.000, $p<0.001$; proximal-posterior area, power $=0.259$, $p=0.404$; central-medial area, power $=0.574, p=0.077$; central-anterior area, power $=0.999, p<0.001$; centrallateral area, power $=0.535, p=0.097$; central-posterior area, $\quad$ power $=0.999, \quad p<0.001 ; \quad$ distal-medial area, power $=0.199, p=0.538$; distal - anterior area, power $=$ 0.862, $p=0.006$; distal-lateral area, power $=0.560, p=$ 0.084 ; distal-posterior area, power $=0.969, p<0.001$.

\section{Results}

The actual and standardized cortical thicknesses are presented in Tables 1 and 2. Regarding the structural characteristics in normal individuals (young group) (Table 3 ), there were no differences in the medial and lateral thicknesses in the proximal, central, and distal diaphysis. The anterior thickness was greater than the posterior thickness in the proximal (men, $p<0.001$; women, $p<$ 0.001 ), central (men, $p<0.001$; women, $p<0.001$ ), and distal diaphysis (men, $p<0.001$; women, $p<0.001$ ).

In terms of sex-related differences (Table 4), all 12 regions showed no statistically significant differences, whereas elderly women possessed the trend of greater cortical thickness than elderly men in the medial and lateral areas of all heights. Regarding the anterior and posterior areas, elderly women exhibited the trend of the lesser cortical thickness than elderly men in the central and distal heights with no statistically significant differences. 
Table 2 Cortical thickness in the tibial diaphysis (standardized values)

\begin{tabular}{|c|c|c|c|c|c|c|c|c|}
\hline \multirow{3}{*}{$\begin{array}{l}\text { Standardized } \\
\text { values } \\
\left(\times 10^{-3}\right)\end{array}$} & \multicolumn{4}{|c|}{ Young group $(n=31)$} & \multicolumn{4}{|c|}{ Elderly group $(n=54)$} \\
\hline & \multicolumn{2}{|c|}{ Men $(n=12)$} & \multicolumn{2}{|c|}{ Women $(n=19)$} & \multicolumn{2}{|c|}{ Men $(n=29)$} & \multicolumn{2}{|c|}{ Women $(n=25)$} \\
\hline & mean & $95 \% \mathrm{Cl}$ & mean & $95 \% \mathrm{Cl}$ & mean & $95 \% \mathrm{Cl}$ & mean & $95 \% \mathrm{Cl}$ \\
\hline \multicolumn{9}{|l|}{ Total diaphysis } \\
\hline Medial & 15.7 & $14.6-16.7$ & 15.9 & $14.4-17.3$ & 17.3 & $16.7-18.0$ & 18.1 & $17.5-18.7$ \\
\hline Lateral & 17.0 & 15.0-19.0 & 14.7 & $13.8-15.5$ & 17.0 & $16.3-17.7$ & 17.4 & $16.6-18.2$ \\
\hline Anterior & 28.1 & $24.6-31.7$ & 25.5 & $23.6-27.4$ & 23.8 & $22.7-25.0$ & 23.5 & $22.5-24.5$ \\
\hline Posterior & 17.5 & $16.5-18.5$ & 18.0 & $16.3-19.8$ & 16.1 & $15.7-16.6$ & 16.0 & $15.5-16.5$ \\
\hline \multicolumn{9}{|c|}{ Proximal diaphysis } \\
\hline Medial & 14.0 & $13.1-14.9$ & 14.1 & $13.2-15.1$ & 16.9 & $16.2-17.6$ & 17.9 & $17.1-18.6$ \\
\hline Lateral & 15.1 & $13.3-17.0$ & 12.8 & $12.3-13.4$ & 16.7 & $16.1-17.4$ & 17.1 & $16.2-18.0$ \\
\hline Anterior & 24.5 & $20.5-28.5$ & 22.7 & $20.7-24.7$ & 22.3 & $21.1-23.4$ & 22.9 & $21.8-23.9$ \\
\hline Posterior & 17.1 & $16.0-18.2$ & 16.7 & $15.1-18.3$ & 16.0 & $15.4-16.5$ & 16.4 & $15.6-17.2$ \\
\hline \multicolumn{9}{|c|}{ Central diaphysis } \\
\hline Medial & 16.3 & $14.5-18.1$ & 16.3 & $14.6-18.0$ & 17.4 & $16.4-18.4$ & 18.2 & $17.4-19.1$ \\
\hline Lateral & 18.3 & $15.7-20.8$ & 15.6 & $14.1-17.1$ & 16.2 & $14.8-17.6$ & 17.4 & $16.4-18.4$ \\
\hline Anterior & 31.1 & $27.6-34.7$ & 28.8 & $26.4-31.2$ & 25.2 & $23.7-26.7$ & 23.7 & $22.5-24.9$ \\
\hline Posterior & 18.4 & $17.3-19.6$ & 19.1 & $17.1-21.2$ & 16.1 & $15.5-16.6$ & 15.4 & $15.0-15.9$ \\
\hline \multicolumn{9}{|l|}{ Distal diaphysis } \\
\hline Medial & 17.5 & $16.1-18.9$ & 18.3 & $16.2-20.4$ & 18.6 & $17.7-19.4$ & 18.9 & $18.2-19.5$ \\
\hline Lateral & 18.4 & $16.2-20.6$ & 16.1 & $14.9-17.3$ & 17.8 & $16.7-19.0$ & 18.1 & $16.9-19.3$ \\
\hline Anterior & 30.2 & $26.5-34.0$ & 26.0 & $24.0-28.0$ & 26.8 & $25.1-28.6$ & 24.6 & $23.1-26.1$ \\
\hline Posterior & 17.1 & $15.9-18.4$ & 18.7 & $16.8-20.7$ & 16.8 & $16.2-17.5$ & 15.6 & $15.1-16.0$ \\
\hline
\end{tabular}

95\% Cl 95\% Confidence interval; standardized values means the actual values divided by the tibia length

With respect to age-related differences (Table 4), elderly women showed greater cortical thickness than young women in the medial $(p<0.001)$ and lateral areas $(p<0.001)$ of the proximal height, and elderly men showed greater cortical thickness than young men in the medial area of the proximal height $(p<0.001)$.
In the anterior and posterior areas, elderly women showed lesser cortical thickness than young women (central-anterior, $\quad p=0.001$; central-posterior, $\quad p<$ 0.001 ; distal-posterior, $p<0.001$ ), and elderly men demonstrated lesser cortical thickness than young men (central-anterior, $p=0.001$ ).

Table 3 Comparison between medial and lateral or between anterior and posterior standardized thickness

\begin{tabular}{|c|c|c|c|c|c|c|c|c|c|}
\hline & & \multicolumn{2}{|c|}{ Young men } & \multicolumn{2}{|c|}{ Young women } & \multicolumn{2}{|c|}{ Elderly men } & \multicolumn{2}{|c|}{ Elderly women } \\
\hline & & $p$ value & Summary & $p$ value & Summary & $p$ value & Summary & $p$ value & Summary \\
\hline \multirow[t]{2}{*}{ Total diaphysis } & $M-L$ & n.s. & - & n.s. & - & n.s. & - & n.s. & - \\
\hline & $A-P$ & $<.001$ & $A>P$ & $<.001$ & $A>P$ & $<.001$ & $A>P$ & $<.001$ & $A>P$ \\
\hline \multirow[t]{2}{*}{ Proximal diaphysis } & $M-L$ & n.s. & - & n.s. & - & n.s. & - & n.s. & - \\
\hline & $A-P$ & $<.001$ & $A>P$ & $<.001$ & $A>P$ & $<.001$ & $A>P$ & $<.001$ & $A>P$ \\
\hline \multirow[t]{2}{*}{ Central diaphysis } & $M-L$ & n.s. & - & n.s. & - & n.s. & - & n.s. & - \\
\hline & $A-P$ & $<.001$ & $A>P$ & $<.001$ & $A>P$ & $<.001$ & $A>P$ & $<.001$ & $A>P$ \\
\hline \multirow[t]{2}{*}{ Distal diaphysis } & $M-L$ & n.s. & - & n.s. & - & n.s. & - & n.s. & - \\
\hline & $A-P$ & $<.001$ & $A>P$ & $<.001$ & $A>P$ & $<.001$ & $A>P$ & $<.001$ & $A>P$ \\
\hline
\end{tabular}

The standardized cortical thickness in each height (proximal, central, and distal diaphysis) of the four groups (young men, young women, elderly men, and elderly women) was compared among the four areas of the axial plane (medial, anterior, lateral, and posterior areas), using one-way ANOVA with Tukey test. M-L= comparison between medial and lateral standardized thickness; $\mathrm{A}-\mathrm{P}=$ comparison between anterior and posterior standardized thickness; $\mathrm{M}=$ medial standardized thickness; $\mathrm{L}=$ lateral standardized thickness; $\mathrm{A}=$ anterior standardized thickness; $\mathrm{P}=$ posterior standardized thickness; $\mathrm{n} . \mathrm{s}$. = $p>.01$ 
Table 4 Sex- and age- related differences

\begin{tabular}{|c|c|c|c|c|c|c|c|c|c|}
\hline & & \multicolumn{4}{|c|}{ Men (M) vs Women (W) (sex-related difference) } & \multicolumn{4}{|c|}{ Young $(\mathrm{Y})$ vs Elder group (E) (age-related difference) } \\
\hline & & \multicolumn{2}{|c|}{ Young group } & \multicolumn{2}{|c|}{ Elderly group } & \multicolumn{2}{|c|}{ Men group } & \multicolumn{2}{|c|}{ Women group } \\
\hline & & $p$ value & Summary & $p$ value & Summary & $p$ value & Summary & $p$ value & Summary \\
\hline \multirow[t]{4}{*}{ Total diaphysis } & M & n.s. & - & n.s. & - & n.s. & - & .002 & $Y<E$ \\
\hline & L & n.s. & - & n.s. & - & n.s. & - & $<.001$ & $Y<E$ \\
\hline & A & n.s. & - & n.s. & - & .003 & $Y>E$ & n.s. & - \\
\hline & $P$ & n.s. & - & n.s. & - & n.s. & - & .009 & $Y>E$ \\
\hline \multirow[t]{4}{*}{ Proximal diaphysis } & M & n.s. & - & n.s. & - & $<.001$ & $Y<E$ & $<.001$ & $Y<E$ \\
\hline & $L$ & n.s. & - & n.s. & - & n.s. & - & $<.001$ & $Y<E$ \\
\hline & A & n.s. & - & n.s. & - & n.s. & - & n.s. & - \\
\hline & $P$ & n.s. & - & n.s. & - & n.s. & - & n.s. & - \\
\hline \multirow[t]{4}{*}{ Central diaphysis } & M & n.s. & - & n.s. & - & n.s. & - & n.s. & - \\
\hline & L & n.s. & - & n.s. & - & n.s. & - & n.s. & - \\
\hline & A & n.s. & - & n.s. & - & .001 & $Y>E$ & .001 & $Y>E$ \\
\hline & $P$ & n.s. & - & n.s. & - & n.s. & - & $<.001$ & $Y>E$ \\
\hline \multirow[t]{4}{*}{ Distal diaphysis } & M & n.s. & - & n.s. & - & n.s. & - & n.s. & - \\
\hline & $\mathrm{L}$ & n.s. & - & n.s. & - & n.s. & - & n.s. & - \\
\hline & A & n.s. & - & n.s. & - & n.s. & - & n.s. & - \\
\hline & $P$ & n.s. & - & n.s. & - & n.s. & - & $<.001$ & $Y>E$ \\
\hline
\end{tabular}

The standardized cortical thickness in each of the 12 regions was compared among the four groups categorized by sex and age (young men, young women, elderly men, and elderly women), using one-way ANOVA with Tukey test. $M=$ medial thickness; $L=$ lateral thickness; $A=$ anterior thickness; $P=$ posterior thickness; n.s. $=p>.01$

\section{Discussion}

The most important finding of the present study was that cortical thickness of the tibial diaphysis reveals ageand sex-related characteristics between non-obese healthy young and elderly subjects depending on the tibial regions. For clinical relevance, the results can be the reference points to clarify the causes of various pathological conditions in lower extremity diseases, such as knee OA.

This study supplied the similar trends observed in young men and women; there were no differences in the medial and lateral thicknesses, while the anterior thickness was greater than the posterior thickness. Cristofolini et al. [25] reported that the geometry of the tibia shows that the diaphysis is shaped so as to resist best to a bending load in a sagittal plane. The linearity was stronger for the area and inertia properties corresponding to a moment in a sagittal plane than in a frontal plane. From the viewpoint of stress fracture, the tibia was the most exposed site for in vivo strain measurements due to accessibility and being a common pathologic site of stress fracture in the lower extremity [26]. The predominant components of force during physiological activities are axial and anteroposterior directions [27]. While axial force generates a state of axial compression, the anteroposterior force component generates a bending moment, which can cause large stress. To adapt itself to large stress, the tibia becomes approximately $50 \%$ stiffer in a sagittal plane (bending stiffness, $5.989 \mathrm{Nm} / \mathrm{mm})$ than in a frontal plane $(3.588$ $\mathrm{Nm} / \mathrm{mm}$ ) [28]. This study's result indicates that the greater anterior cortical thickness is indispensable to resist the bending moment by the anteroposterior force.

Sex-related differences were not shown at all regions in young and elderly individuals. In the longitudinal study from childhood to early adulthood, sex differences in the distal tibia and radius of growth-related adaptations in bone microarchitecture, geometry, density, and strength across adolescent growth were shown [29]. In the femur, the sex-related differences demonstrated that cortical thickness was greater in men than in women, depending on the region of the whole femur [1]. The study to assess the cortical porosity and thickness of the tibia, using high-resolution CT and linear finite element analysis, exhibited that regional porosity and thickness provided increased sensitivity to sex differences compared to the global analysis at the tibia $(-17 \%$ in women) [30]. Sex-related difference in cortical thickness varies in each region of each bone, depending on many factors, especially related to biomechanics, osteoporosis, and hormones [1, 29-31], whereas the tibia possessed similar thickness in all regions for either young or elderly individuals in this study.

Regarding the age-related difference, elderly individuals showed greater cortical thickness in the medial and lateral areas of the proximal diaphysis than young 
individuals. In the medial-lateral side in the coronal plane, lower leg alignment may be associated with this. In normal subjects, elderly individuals possess slight varus alignment compared to young individuals [32]. Varus coronal alignment is correlated with the inclination of the medial compartment of the proximal tibia [10]. The structure of the proximal tibial metaphysis is mechanically weak due to its low bone mineral density and has laterality between the medial and lateral knee compartments [33, 34]. The laterality of bone mineral density can affect the proximal tibial inclination; thus, the proximal tibia is the key factor for deformation by aging and knee OA [5, 10, 32]. The result of this study, showing greater thickness in the medial and lateral areas of the proximal diaphysis, may explain the remodeling of the proximal tibia due to aging. In terms of remodeling, the periosteum side and medullary cavity side switch to either the compression side or tension side [35]. Remodeling includes "bone formation by compression" and "bone resorption by tension." Load bearing in the medial proximal tibia works at the medial cortical bone as "compression" in the periosteum side and "tension" in the medullary cavity side. In contrast, at the lateral cortical bone of the proximal tibia, it works as "compression" in the medullary cavity side and "tension" in the periosteum side. Then, it is probable that cortical thickness in not only the medial area but also the lateral areas of the proximal diaphysis is greater in elderly individuals by remodeling. This age-related difference implies that the medial proximal tibia gradually deforms (inclines medially) with aging. Higano et al. [5] demonstrated that the greater medial cortical thickness in the proximal tibia before the development of knee OA was associated with its progression. Their finding indicates that cortical thickness can be the index of load distribution and its related deformity. As our hypothesis, it is assumed that the consecutive mechanical burden in the medial compartment of the proximal tibia throughout life gradually causes deformation, including the change in cortical thickness with aging, such as medial inclination of the proximal tibia and varus alignment, and leads to the development and progression of varus knee OA.

Elderly individuals have lesser thickness of the anterior and posterior areas than young individuals (Tables 1 and 2). Gradual bone loss is common with aging. In women, the prevalence of osteoporosis rapidly increased at the age of 70 years. In men, the prevalence increased at the age of 80 years [31]. The correlation between cortical thickness and bone mineral density, which is the parameter of osteoporosis, has also been reported [36]. Lesser anterior and posterior cortical thicknesses in elderly individuals in the present study may be due to osteoporosis and its related factors, rather thickening by remodeling. As structural characteristics, the tibial diaphysis in the sagittal plane (anteroposterior plane) is originally stronger than that in the coronal plane [25] so that the macrostructural deformity in the sagittal plane, such as bony bowing, may less likely to occur, leading to less remodeling by deformation in the tibia.

The introduction of this evaluation in clinical practice has the disadvantage of a radiation exposure from CTscan. The potential adverse effects of radiation exposure have become a concern $[37,38]$. As radiation exposure was similar to that of common clinical settings, it did not directly cause adverse effects. However, healthy young women were exposed to radiation at a part of their pelvises for this study; hence, they need to be carefully observed. In the future study, one protocol for CT should reduce radiation dose while maintaining image quality.

\section{Limitations}

This study has limitations. First, the accuracy of this method depended on osteoporosis and CT scanning conditions, such as pixel and voxel size. Treece et al. [23] demonstrated a high degree of accuracy using the lesser cortical thickness of the femoral neck $[3,23]$. This study's use of greater cortical thickness of the tibial diaphysis than that of the femoral neck can be assumed to be effective. Additionally, the size ranges of the pixels and voxels in this study were relatively narrow, limiting the effect of the CT scanning conditions on calculations of cortical thickness and reconstruction of 3D models. Second, while the statistical power of this study was sufficient, the sample size was not large, especially in young men. Third, although the regions were strictly divided based on a coordinate system, bony torsional deformities may have influenced the demarcation of the regions and study results. All subjects were healthy so that the rotational effect is likely minimum. Fourth, precision obtained via all processes in the current study excluded CT scans because radiation exposure would increase two or three times if the CT data for each subject were acquired repeatedly, which is not ethically permissible for a research study. Lastly, osteoporosis was not assessed using dual-energy X-ray absorptiometry for elderly individuals, making it impossible to accurately evaluate any association between cortical thickness and osteoporosis. Further assessments should be included in future studies.

With regard to clinical relevance, these normal subject data have the potential to become reference points to clarify the causes of various pathological conditions in lower extremity diseases, such as knee OA. 


\section{Conclusions}

Age- and sex-related characteristics in cortical thickness of the tibial diaphysis between non-obese healthy young and elderly subjects are different depending on the tibial regions. The results of this study are of clinical relevance as reference points to clarify the causes of various pathological conditions for diseases.

\section{Abbreviations}

OA: Knee osteoarthritis; CT: Computed tomography; SD: Standard deviation; BMI: Body mass index; Cl: Confidence interval; IRB: Institutional review board; ANOVA: One-way analysis of variance

\section{Authors' contributions}

Conception and design: Drs. Koga Y, Mochizuki T. Provision of study materials or patients: Drs. Maeda K, Mochizuki T. Collection of data and analysis and interpretation of the data: Drs. Maeda K, Mochizuki T, Hokari S, Someya K, Katsumi R, Tanifuji O, Koga H. Technical support for the system of extremity alignment assessment system: Drs. Kobayashi K, Sakamoto M, Morise Y. Drafting of the article: Drs. Mochizuki T, Maeda K. Final approval of the article: Drs. Maeda K, Mochizuki T, Kobayashi K, Tanifuji O, Someya K, Hokari S, Katsumi R, Morise Y, Koga H, Sakamoto M, Koga Y, Kawashima H. The author (s) read and approved the final manuscript.

\section{Funding}

This study received KAKENHI from grants-in-aid for scientific research in Japan society for the promotion of science.

\section{Availability of data and materials}

References see PubMed.gov.

\section{Ethics approval and consent to participate}

The study was approved by the Institutional Review Board in Niigata University. Appropriate consents, permissions and releases were obtained.

\section{Consent for publication}

All presentations had consent to publish.

\section{Competing interests}

The authors did not receive and will not receive any benefits or funding from any commercial party related directly or indirectly to the subject of this article.

\section{Author details}

${ }^{1}$ Division of Orthopedic Surgery, Department of Regenerative and Transplant Medicine, Niigata University Graduate School of Medical and Dental Science, 1-757 Asahimachi-dori Chuo-ku, Niigata City, Niigata 951-8510, Japan. ${ }^{2}$ School of Health Sciences, Faculty of Medicine, Niigata University, Niigata, Japan. ${ }^{3}$ Graduate School of Science and Technology, Niigata University, Niigata, Japan. ${ }^{4}$ Department of Orthopedic Surgery, Nioji Onsen Hospital, Niigata, Japan.

Received: 27 July 2020 Accepted: 28 September 2020 Published online: 06 October 2020

\section{References}

1. Someya K, Mochizuki T, Hokari S, Tanifuji O, Katsumi R, Koga H, Takahashi Y, Kobayashi K, Morise Y, Sakamoto M, Koga Y, Endo N (2020) Age- and sexrelated characteristics in cortical thickness of femoral diaphysis for young and elderly subjects. J Bone Miner Metab 38:533-543. https://doi.org/10. 1007/s00774-019-01079-9

2. Mayhew PM, Thomas CD, Clement JG, Loveridge N, Beck TJ, Bonfield W, Burgoyne CJ, Reeve J (2005) Relation between age, femoral neck cortical stability, and hip fracture risk. Lancet 366:129-135. https://doi.org/10.1016/ S0140-6736(05)66870-5

3. Poole KES, Treece GM, Mayhew PM, Vaculik J, Dungl P, Horak M, Štěpan J J (2012) Cortical thickness mapping to identify focal osteoporosis in patients with hip fracture. PLoS One https://doi: https://doi.org/10.1371/journal.pone. 0038466
4. Verhulp E, van Rietbergen B, Huiskes R (2008) Load distribution in the healthy and osteoporotic human proximal femur during a fall to the side. Bone 42:30-35. https://doi.org/10.1016/j.bone.2007.08.039

5. Higano Y, Hayami T, Omori G, Koga Y, Endo K, Endo N (2016) The varus alignment and morphologic alterations of proximal tibia affect the onset of medial knee osteoarthritis in rural Japanese women: case control study from the longitudinal evaluation of Matsudai knee osteoarthritis survey. J Orthop Sci 21:166-171. https://doi.org/10.1016/j. jos.2015.12.002

6. Koga Y. Osteoarthritic of the knee (2008) Epidemiology, biomechanics, and conservative treatment [In Japansese] Chapter 2:41-65

7. Mochizuki T, Tanifuji O, Koga Y, Sato T, Kobayashi K, Nishino K, Watanabe S, Ariumi A, Fujii T, Yamagiwa H, Omori G, Endo N (2017) Sex differences in femoral deformity determined using three-dimensional assessment for osteoarthritic knees. Knee Surg Sports Traumatol Arthrosc 25:468-476. https://doi.org/10.1007/s00167-016-4166-2

8. Mochizuki T, Tanifuji O, Koga Y, Hata R, Mori T, Nishino K, Sato T, Kobayashi K, Omori G, Sakamoto M, Tanabe Y, Endo N (2017) External torsion in a proximal tibia and internal torsion in a distal tibia occur independently in varus osteoarthritic knees compared to healthy knees. J Orthop Sci 22:501505. https://doi.org/10.1016/j.jos.2017.01.002

9. Mochizuki T, Tanifuji O, Koga Y, Sato T, Kobayashi K, Watanabe S, Fujii T, Yamagiwa H, Katsumi R, Koga H, Omori G, Endo N (2018) Correlation between posterior tibial slope and sagittal alignment under weight-bearing conditions in osteoarthritic knees. PLoS One. https://doi.org/10.1371/journal. pone. 0202488

10. Mochizuki T, Koga Y, Tanifuji O, Sato T, Watanabe S, Koga H, Kobayashi K, Omori G, Endo N (2019) Effect on inclined medial proximal tibial articulation for varus alignment in advanced knee osteoarthritis. J Exp Orthop. https:// doi.org/10.1186/s40634-019-0180-x

11. Mochizuki T, Koga Y, Mori T, Nishino K, Kobayashi K, Tanifuji O, Sato T, Katsumi R, Koga H, Omori G, Tanabe Y (2019) Articular surface of the medial proximal tibia is aligned parallel to the ground in three dimensional space under weight-bearing conditions in healthy and varus osteoarthritic knees. Knee Surg Sports Traumatol Arthrosc. https://doi.org/10.1007/s00167-01905829-0

12. Omori G (2005) Epidemiology of knee osteoarthritis. Acta Med Biol 53:1-11

13. Omori G, Koga $Y$, Tanaka M, Nawata A, Watanabe H, Narumi K, Endoh K (2013) Quadriceps muscle strength and its relationship to radiographic knee osteoarthritis in Japanese elderly. J Orthop Sci 18:536-542. https://doi.org/ 10.1007/s00776-013-0383-4

14. Omori G, Narumi K, Nishino K, Nawata A, Watanabe H, Tanaka M, Endoh K, Koga $Y$ (2016) Association of mechanical factors with medial knee osteoarthritis: a cross-sectional study from Matsudai knee osteoarthritis survey. J Orthop Sci 21:463-468. https://doi.org/10.1016/j.jos.2016.03.006

15. Shiozaki H, Koga Y, Omori G, Tamaki M (1999) Obesity and osteoarthritis of the knee in women: results from the Matsudai knee osteoarthritis survey. Knee 6:189-192

16. Takagi S, Omori G, Koga H, Endo K, Koga Y, Nawata A, Endo N (2017) Quadriceps muscle weakness is related to increased risk of radiographic knee OA but not its progression in both women and men: the Matsudai knee osteoarthritis survey. Knee Surg Sports Traumatol Arthrosc 26:26072614. https://doi.org/10.1007/s00167-017-4551-5

17. Tanishi N, Yamagiwa H, Hayami T, Mera H, Koga Y, Omori G, Endo N (2009) Relationship between radiological knee osteoarthritis and biochemical markers of cartilage and bone degradation (urine CTX-II and NTX-I): the Matsudai knee osteoarthritis survey. J Bone Miner Metab 27:605-612. https://doi.org/10.1007/s00774-009-0077-3

18. Tanishi N, Yamagiwa H, Hayami T, Mera H, Koga Y, Omori G, Endo N (2014) Usefulness of urinary CTX-II and NTX-I in evaluating radiological knee osteoarthritis : the Matsudai knee osteoarthritis survey. J Orthop Sci 19:429436. https://doi.org/10.1007/s00776-014-0535-1

19. Buie HR, Campbell GM, Klinck RJ, MacNeil JA, Boyd SK (2007) Automatic segmentation of cortical and trabecular compartments based on a dual threshold technique for in vivo micro-CT bone analysis. Bone 41:505-515. https://doi.org/10.1016/j.bone.2007.07.007

20. Hangartner TN (2007) Thresholding technique for accurate analysis of density and geometry in QCT, PQCT and CT images. J Musculoskelet Neuronal Interact 7:9-16

21. Prevrhal S, Engelke K, Kalander W.A (1999) Accuracy limits for the determination of cortical width and density: the influence of object size and 
CT imaging parameters. Phys Med Biol 44:751-764. doi: https://doi.org/10. 1088/0031-9155/44/3/017

22. Prevrhal S, Fox JC, Shepherd JA, Genant HK (2003) Accuracy of CT-based thickness measurement of thin structures: modeling of limited spatial resolution in all three dimensions. Med Phys 30:1-8. https://doi.org/10.1118/ 1.1521940

23. Treece GM, Gee AH, Mayhew PM, Poole KE (2010) High resolution cortical bone thickness measurement from clinical CT data. Med Image Anal 14: 276-290. https://doi.org/10.1016/j.media.2010.01.003

24. Treece GM, Gee AH (2015) Independent measurement of femoral cortical thickness and cortical bone density using clinical $\mathrm{CT}$. Med Image Anal 20: 249-264. https://doi.org/10.1016/j.media.2014.11.012

25. Cristofolini L, Angeli E, Juszczyk JM, Juszczyk MM (2013) Shape and function of the diaphysis of the human tibia. J Biomech 46:1882-1892. https://doi. org/10.1016/j.jbiomech.2013.04.026

26. Al Nazer R, Lanovaz J, Kawalilak C, Johnston JD, Kontulainen S (2012) Direct in vivo strain measurements in human bone-a systematic literature review. J Biomech 45:27-40. https://doi.org/10.1016/j.jbiomech.2011.08.004

27. Mundermann A, Dyrby COD, Lima DD, Colwell CW Jr, Andriacchi TP (2008) In vivo knee loading characteristics during activities of daily living as measured by an instrumented total knee replacement. J Orthop Res 26: 1167-1172. https://doi.org/10.1002/jor.20655

28. Minns RJ, Campbell J, Bremble GR (1975) The bending stiffness of the human tibia. Calcif Tissue Res 17:165-168. https://doi.org/10.1007/ BF02547289

29. Gabel L, Macdonald HM, McKay HA (2017) Sex differences and growthrelated adaptations in bone microarchitecture, geometry, density and strength from childhood to early adulthood: a mixed longitudinal HR-pQCT study. J Bone Miner Res 32:250-263. https://doi.org/10.1002/jbmr.2982

30. Kazakia GJ, Nirody JA, Bernstein G, Sode M, Burghardt AJ, Majumdar S (2013) Age-and gender-related differences in cortical geometry and microstructure: improved sensitivity by regional analysis. Bone 52:623-631. https://doi.org/10.1016/j.bone.2012.10.031

31. Alswat KA (2017) Gender disparities in osteoporosis. J Clin Med Res 9:382387. https://doi.org/10.14740/jocmr2970w

32. Matsumoto T, Hashimura M, Takayama K, Ishida K, Kawakami Y, Matsuzaki T, Nakano N, Matsushita T, Kuroda R, Kurosaka M (2015) A radiographic analysis of alignment of the lower extremities-initiation and progression of varus-type knee osteoarthritis. Osteoarthr Cartil 23:217-223. https://doi.org/ 10.1016/j.joca.2014.11.015

33. Akamatsu Y, Mitsugi N, Taki N, Takeuchi R, Saito T (2009) Relationship between low bone mineral density and varus deformity in postmenopausal women with knee osteoarthritis. J Rheumatol 36:592-597. https://doi.org/10 3899/jrheum.080699

34. Lo GH, Zhang Y, McLennan C, Niu J, Kiel DP, McLean RR, Aliabadi P, Felson DT, Hunter DJ (2006) The ratio of medial to lateral tibial plateau bone mineral density and compartment-specific tibiofemoral osteoarthritis. Osteoarthr Cartil 14:984-990. https://doi.org/10.1016/j.joca.2006.04.010

35. Currey JD (1984) What should bones be designed to do? Calcif Tissue Int 36:S7-S10. https://doi.org/10.1007/BF02406127

36. Webber T, Patel SP, Pensak M, Fajolu O, Rozental TD, Wolf JM (2015) Correlation between distal radial cortical thickness and bone mineral density. J Hand Surg Am 40:493-499. https://doi.org/10.1016/j.jhsa.2014.12.015

37. Marant-Micallef C, Shield KD, Vignat J, Cléro E, Kesminiene A, Hill C, Rogel A, Vacquier B, Bray F, Laurier D, Soerjomataram I (2019) The risk of cancer attributable to diagnostic medical radiation: estimation for France in 2015. Int J Cancer 144:2954-2963. https://doi.org/10.1002/ijc.32048

38. Mehyar LS, Abu-Arja MH, Stanek JR, Elbeshlawi I, AbdelBaki MS (2019) The risk of developing secondary central nervous system tumors after diagnostic irradiation from computed tomography in pediatrics: a literature review. Pediatr Neurol 98:18-24. https://doi.org/10.1016/.jpediatrneurol.2019.03.028

\section{Publisher's Note}

Springer Nature remains neutral with regard to jurisdictional claims in published maps and institutional affiliations.

\section{Submit your manuscript to a SpringerOpen ${ }^{\circ}$ journal and benefit from:}

- Convenient online submission

- Rigorous peer review

- Open access: articles freely available online

- High visibility within the field

- Retaining the copyright to your article

Submit your next manuscript at $\boldsymbol{\nabla}$ springeropen.com 